\title{
The burden of waiting: wait times for pediatric surgical procedures in Quebec and compliance with national benchmarks
}

\author{
Brandon Arulanandam \\ Marc Dorais, MSc \\ Patricia $\mathrm{Li}^{*}, \mathrm{MD}, \mathrm{MSc}$ \\ Dan Poenaru*, MD, PhD
}

*Share senior authorship.

Accepted Mar. 12, 2020

\author{
Correspondence to: \\ D. Poenaru \\ Harvey E. Beardmore Division of \\ Pediatric Surgery \\ Montreal Children's Hospital \\ Room B04.2028 \\ 1001 Decarie Blvd \\ Montreal OC H4A 3J1 \\ dan.poenaru@mcgill.ca
}

DOI: $10.1503 /$ cjs.020619

\begin{abstract}
Background: Wait time information and compliance with national guidelines are limited to a few adult conditions in the province of Quebec. We aimed to assess compliance with Paediatric Canadian Access Targets for Surgery (P-CATS) guidelines and determine the burden incurred due to waiting for 3 common elective surgical conditions (inguinal hernia, cryptorchidism and hypospadias) in a pediatric population.
\end{abstract}

Methods: We carried out a population-based retrospective cohort study of randomly selected children residing in Quebec without complex chronic medical conditions, using administrative databases belonging to the Régie de l'assurance maladie du Québec for the period 2010-2013. Disability-adjusted life years (DALYs) were calculated to measure the burden due to waiting. Multivariate forward regression identified risk factors for compliance with national guidelines.

Results: Surgical wait time information was assessed for 1515 patients, and specialist referral wait time was assessed for 1389 patients. Compliance with P-CATS benchmarks was $76.6 \%$ for seeing a specialist and $60.7 \%$ for receiving surgery. Regression analysis identified older age $(p<0.0001)$ and referring physician specialty $(p=0.001)$ as risk factors affecting specialist referral wait time target compliance, whereas older age $(p=0.040)$, referring physician specialty $(p=0.043)$ and surgeon specialty $(p=$ 0.002 ) were significant determinants in surgical wait time compliance. The total burden accrued due to waiting beyond benchmarks was 35 DALYs.

Conclusion: Our results show that provincial compliance rates with wait time benchmarks are still inadequate and need improvement. Patient age and physician specialty were both found to have significant effects on wait time target compliance.

Contexte : L'information sur les temps d'attente et le respect des lignes directrices nationales au Québec est limitée à quelques affections chez les adultes. Nous avons voulu évaluer le respect des objectifs canadiens en matière d'accès aux chirurgies pédiatriques (P-CATS) et déterminer le fardeau associé à l'attente pour 3 affections courantes nécessitant une intervention chirurgicale non urgente (hernie inguinale, cryptorchidie et hypospadias) chez une population pédiatrique.

Méthodes : Pour ce faire, nous avons mené une étude de cohorte populationnelle rétrospective portant sur des enfants vivant au Québec et n'ayant pas de problèmes de santé chroniques complexes. Leur sélection aléatoire a été faite à partir de bases de données administratives appartenant à la Régie de l'assurance maladie du Québec pour la période de 2010 à 2013 . Nous avons calculé les années de vie ajustées en fonction de l'incapacité (AVAI) pour mesurer le fardeau associé à l'attente. Une régression ascendante multivariée a permis de relever les facteurs de risque relatifs au respect des lignes directrices nationales.

Résultats : Nous avons évalué les données sur le temps d'attente pour une intervention chirurgicale chez 1515 patients, et sur le temps d'attente pour la consultation d'un spécialiste chez 1389 patients. Les valeurs de référence pour le respect des P-CATS étaient de 76,6\% pour la consultation d'un spécialiste et de $60,7 \%$ pour la réalisation d'une intervention. L'analyse de régression a montré que l'âge plus avancé $(p<0,0001)$ et la spécialité du médecin traitant $(p=0,001)$ étaient des facteurs de risque pour la consultation d'un spécialiste, tandis que l'âge plus avancé $(p=0,040)$, la spécialité du médecin traitant $(p=0,043)$ et la spécialité du chirurgien $(p=0,002)$ étaient des déterminants significatifs du respect des objectifs d'attente pour une intervention. Le fardeau total causé par l'attente au-delà des valeurs de référence était de 35 AVAI.

Conclusion : Nos résultats montrent que le taux provincial de respect des lignes directrices d'attente demeure inadéquat et doit être amélioré. L'âge des patients et la spécialité des médecins ont tous deux un effet significatif sur le respect des objectifs d'attente. 
$\mathbf{R}$ eceiving a diagnosis requiring surgical intervention is a stressful moment for many patients and their families, ${ }^{1,2}$ one that can be aggravated by a long wait time for treatment. ${ }^{3,4}$ Longer wait times have been associated with lower quality of life, worsened psychological health and negative social consequences., ${ }^{5,6}$ Patients' treatment outcomes may also be adversely affected by prolonged waiting. ${ }^{7-9}$ Moreover, long wait times carry economic consequences: a study carried out by the Fraser Institute revealed that waiting for medically necessary interventions cost the Canadian economy $\$ 2.1$ billion in lost wages in 2018 alone. ${ }^{10}$

Canadians are highly concerned with wait times for medical procedures, ${ }^{11}$ and the federal government has taken note, ${ }^{12}$ leading to online reporting metrics ${ }^{13,14}$ as well as the creation of benchmarks. In pediatric surgery, such benchmarks for timely access to specialists and subsequent treatment were created by the Canadian Paediatric Surgical Wait Times (CPSWT) Project. ${ }^{12,15}$ Provincially, one of the Quebec health care system's challenges is the long wait lists for specialists, leading to subpar wait times compared with Canadian and international averages. ${ }^{16}$ While the issue of wait times for adult conditions has gained more attention in recent years, ${ }^{17}$ wait times plaguing the pediatric population remain underreported. Despite existing treatment benchmarks outlined in the Paediatric Canadian Access Targets for Surgery (P-CATS), ${ }^{15}$ there is no information on their implementation and compliance in the province of Quebec.

Three of the most common pediatric surgical conditions are inguinal hernia, ${ }^{18,19}$ cryptorchidism ${ }^{20,21}$ and hypospadias. ${ }^{22}$ The goal of our study was to examine compliance with P-CATS benchmarks for these 3 common elective surgical conditions in a Quebec pediatric population sample. We also quantified the health burden accrued from waiting by applying disability-adjusted life years (DALYs), a metric that measures morbidity and mortality attributable to different risk factors and diseases, ${ }^{23}$ to the time spent waiting beyond national benchmarks.

\section{Methods}

\section{Study design}

We carried out a population-based retrospective cohort study of randomly selected children (aged 2 to 16 years on Jan. 1, 2012) residing in Quebec who did not have complex chronic medical conditions and were insured by the Régie de l'assurance maladie du Québec (RAMQ) with a valid health care card for the period 2010-2013. Since Quebec has a universal health care system in which all permanent residents are insured for medically required services under the Public Health Insurance Plan, ${ }^{24}$ all interactions with the health care system are recorded in RAMQ's administrative databases.

\section{Data sources}

We used 2 RAMQ administrative databases: the Physician Service Claims Database (physician remunerated services across all clinical settings), and the Registered Persons Database (patient demographics). The RAMQ employs unique randomized patient ID numbers to link these 2 databases anonymously.

\section{Cohort identification}

The RAMQ databases contained a random sample of patients without complex chronic medical conditions. Among this sample of patients, those receiving surgery for inguinal hernia, cryptorchidism or hypospadias repair in 2010-2013 were included in the study. Children from 3 health regions in Northern Quebec were excluded, as the health care resources and delivery in those regions differs from the rest of Quebec. Patients without a visit to a surgical specialist for the same condition as their surgery were also excluded. Telehealth visits were not included, as they were not readily available for general surgery or urology in the province of Quebec in 2013.25

\section{Outcomes}

The primary outcome was compliance with P-CATS benchmark times. This benchmark assigns patients different target times based on whether they are younger or older than 1 year at the time of diagnosis ${ }^{15}$ (Appendix 1, available at canjsurg.ca/020619-a1). According to P-CATS, wait times to see a surgical specialist should not exceed 1-6 weeks for inguinal hernia and 3-6 months for cryptorchidism and hypospadias, depending on patient age. ${ }^{15}$ This wait time was defined as the time from referral to the initial specialist consultation, ${ }^{15}$ hereafter referred to as "wait time 1" (WT1). Likewise, wait times for surgery should not exceed 3-12 weeks for inguinal hernia, 3-12 months for cryptorchidism and 6-12 months for hypospadias. ${ }^{15}$ P-CATS defines this wait time as the time between the date on which a decision is made to proceed with surgery and the actual surgery date, ${ }^{15}$ and in the current study it was referred to as "wait time 2" (WT2). We therefore identified the wait time to see a surgical specialist as the time elapsed between the patient's first surgical specialist visit and the most recent family physician/ pediatrician visit (WT1), and wait time for surgery as the time elapsed between the most recent visit to the surgical specialist and the date of surgery (WT2) (Fig. 1).

As the general consensus in the literature is that surgery for children with cryptorchidism and hypospadias is not required before 6 months of age, ${ }^{26-31}$ patients younger than 6 months receiving surgery for these 2 conditions were considered to have a wait time for surgery of 0 days. If they were seen by a surgical specialist before 6 months of age, 


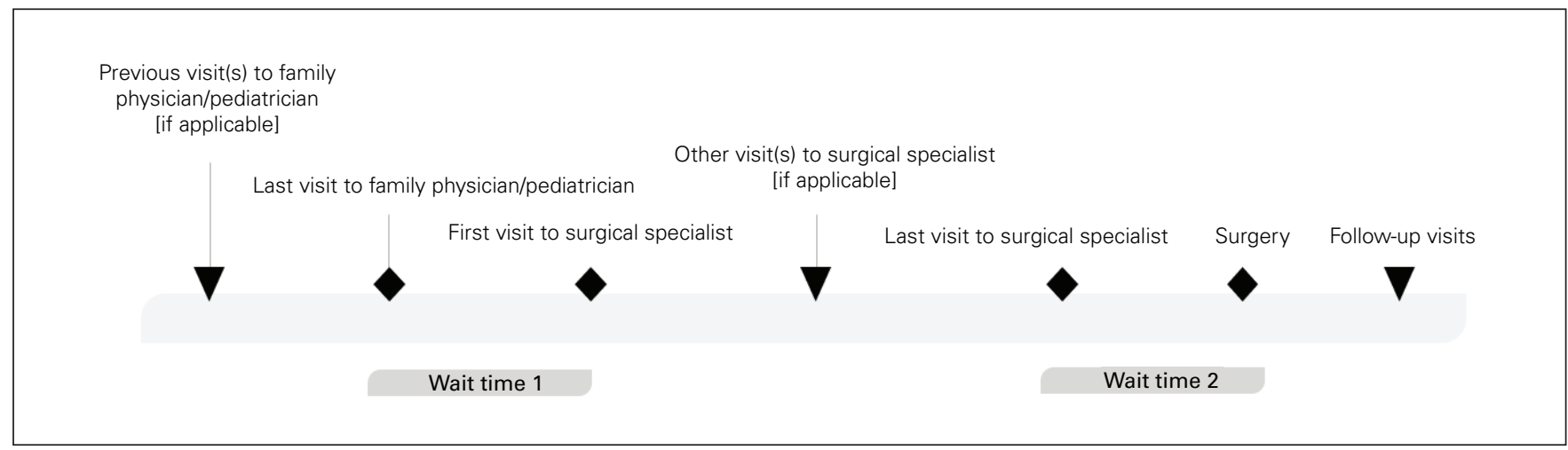

Fig. 1. Pediatric surgical wait times along the continuum of care.

but received surgery after they were 6 months old, then their wait time was considered to be the time elapsed between the 6 month age point and the surgery.

\section{Disability-adjusted life years}

As a secondary outcome to estimate the burden accrued due to waiting, we calculated disability-adjusted life years (DALYs) according to a standard formula that comprises 2 terms: years of life lost (YLL) and years lost due to disability (YLD), where YLD is measured using conditionspecific disability weights ${ }^{23}$ (DWs): DALY $=$ YLL + YLD, where $\mathrm{YLL}=\mathrm{N} \times \mathrm{L}$ and $\mathrm{YLD}=\mathrm{I} \times \mathrm{DW} \times \mathrm{L}$. In these equations, $\mathrm{N}$ is the number of deaths, $\mathrm{L}$ is the average time spent waiting beyond recommended targets, and $\mathrm{I}$ is the number of incident cases.

As none of the 3 conditions under study is fatal (the exception, in strangulated inguinal hernias, is exceedingly rare), the number of years of life lost was assumed to be nil. For patients without a WT1, DALYs were calculated only for WT2. We used DWs of 0.100 for inguinal hernia, ${ }^{32}$ 0.115 for cryptochidism ${ }^{32}$ and 0.120 for hypospadias. ${ }^{23,32}$

\section{Covariables}

Covariables under study included sex (applicable only to the inguinal hernia cohort), age at the time of surgery, number of visits to the surgical specialist, surgeon's specialty, type of primary care provider, region of residence, rurality, and a combined material and social deprivation index. ${ }^{33,34}$ Region, rurality and the deprivation index were determined based on RAMQ data available for each patient as of Jan. 1, 2012.

The usual providers of primary care were divided, based on a previously published algorithm, ${ }^{35}$ into the 3 main types that provide care for children in Quebec: pediatricians; family physicians that are part of a team-based, reformed primary care model known as Family Medicine Groups (FMGs); and family physicians not part of FMGs. The physician identified by this algorithm may have differed from the physician who ultimately referred the child to a surgeon in the present study; the latter physician was classified as either a pediatrician or a family physician based on their specialty code in the RAMQ databases. Rurality was based on the Census Metropolitan Areas (CMA) and Census Agglomeration (CA) Influenced Zones developed by Statistics Canada and categorized based on population as CMA or "urban" (> 100000$)$, CA or "small cities" (10000-100000), and "rural" $(<10000) .{ }^{36-38}$ The deprivation index, developed by the Institut national de santé publique du Québec (INSPQ), was used as a proxy for patient socioeconomic status and consisted of grouping patients into 5 quintiles based on social and material deprivation drawn from census data. ${ }^{33}$ The 5 quintiles were "privileged on both dimensions" (Q1), "slightly deprived" (Q2), "privileged on one dimension but deprived on the other" (Q3 and Q4) and "deprived on both dimensions" (Q5). ${ }^{39}$

\section{Statistical analysis}

We used univariate logistic regression to model the relationship between compliance with P-CATS benchmark times and different factors for each surgical condition. Regressions were carried out for the following covariables: age at the time of surgery, rurality, socioeconomic status, number of visits to the specialist, and the specialty of both the patient's primary care physician and surgeon. The final analysis was carried out as multivariate forward logistic regression. Only significant variables were included in the final model for each condition, with the exception of age at the time of surgery, which was included in all final models because of its well-known effect on wait times.

All analyses were carried out using SAS version 9.4 (SAS Institute Inc.).

\section{Ethics approval}

The RAMQ data were obtained with approval by the Commission d'accès à l'information du Québec. This study was approved by the McGill University Health Centre Research Ethics Board. 


\section{Results}

\section{Descriptive results}

The study cohort initially included all 673189 patients without complex chronic medical conditions found in the random sample obtained from the RAMQ's administrative databases. Among these we first identified and retained, via physician billing codes, 2442 patients who had undergone a surgical procedure to treat inguinal hernia, cryptorchidism or hypospadias. Among the retained patients, we excluded those who did not visit a surgical specialist (general/pediatric surgeon or urologist), leaving 2138 patients. We did not differentiate between "general surgeons" and "pediatric general surgeons" because the RAMQ databases group them together under the specialty of general surgery. Patients without a specialist visit containing an International Classification of Diseases (ICD) diagnostic code for the same condition as the surgery were also excluded. The remaining 1515 patients formed the study cohort for the measurement of compliance with wait time benchmarks to receive surgery (cohort A) (Fig. 2).

To calculate compliance with wait time benchmarks to see a surgical specialist, an initial visit to a referring general practitioner or pediatrician is necessary. However, within cohort $\mathrm{A}$, not all patients had recorded physician visits to a family physician or pediatrician before the first specialist visit in the data sample. To enable calculation of this compliance rate without reducing the number of patients forming cohort A, only patients with these prior visits were grouped into a second cohort (cohort B) comprising 1389 patients (Fig. 2).

Compliance with wait times to receive surgery and to see a surgical specialist was calculated for 860 and 813 inguinal hernia patients, 551 and 489 cryptorchidism patients, and 104 and 87 hypospadias patients, respectively. The overall median age at surgery was 5.4 (interquartile range [IQR] 3.3-8.4) years. Demographic and clinical characteristics are presented in Table 1.

Overall, compliance with P-CATS benchmarks was $76.6 \%$ to see a specialist and $60.7 \%$ to receive surgery. Of

\section{Table 1. Patient characteristics by condition}

\begin{tabular}{|c|c|c|c|}
\hline \multirow[b]{2}{*}{ Characteristic } & \multicolumn{3}{|c|}{ Group; no. $(\%)^{*}$} \\
\hline & $\begin{array}{l}\text { Inguinal hernia } \\
\qquad(n=860)\end{array}$ & $\begin{array}{l}\text { Cryptorchidism } \\
\qquad(n=551)\end{array}$ & $\begin{array}{c}\text { Hypospadias } \\
(n=104)\end{array}$ \\
\hline Male sex & $590(68.6)$ & $551(100)$ & $104(100)$ \\
\hline $\begin{array}{l}\text { Age at surgery, yr; } \\
\text { median (IQR) }\end{array}$ & $5.7(3.9-8.3)$ & $5.1(2.7-9.5)$ & $2.9(2.0-5.1)$ \\
\hline \multicolumn{4}{|l|}{ Rurality $\uparrow$} \\
\hline Urban ( > 100000$)$ & $638(74.2)$ & $359(65.2)$ & $68(61.5)$ \\
\hline $\begin{array}{l}\text { Small cities } \\
(10000-100000)\end{array}$ & $91(10.6)$ & $74(13.4)$ & $15(14.4)$ \\
\hline Rural $(<10000)$ & $129(15.0)$ & $117(21.2)$ & 19 (18.3) \\
\hline $\begin{array}{l}\text { No. visits to specialist; } \\
\text { median (IQR) }\end{array}$ & $1(1-1)$ & $1(1-2)$ & $1(1-1)$ \\
\hline \multicolumn{4}{|l|}{$\begin{array}{l}\text { Socioeconomic } \\
\text { status } \neq\end{array}$} \\
\hline Q1 (least deprived) & $208(24.2)$ & $121(22.0)$ & $23(22.1)$ \\
\hline Q2 & $188(21.9)$ & $120(21.8)$ & $21(20.2)$ \\
\hline Q3 & $150(17.4)$ & 93 (16.9) & $25(24.0)$ \\
\hline Q4 & $122(14.2)$ & 91 (16.5) & $15(14.4)$ \\
\hline Q5 (most deprived) & $164(19.1)$ & $105(19.1)$ & $13(12.5)$ \\
\hline \multicolumn{4}{|l|}{ Surgeon specialty } \\
\hline General surgery & $852(99.1)$ & $145(26.3)$ & $5(4.8)$ \\
\hline Urology & $8(0.9)$ & $406(73.7)$ & 99 (95.2) \\
\hline \multicolumn{4}{|l|}{ Primary care provider } \\
\hline FMG physician & $219(25.5)$ & $174(31.6)$ & $29(27.9)$ \\
\hline $\begin{array}{l}\text { Non-FMG family } \\
\text { physician }\end{array}$ & $187(21.7)$ & $114(20.7)$ & $25(24.0)$ \\
\hline Pediatrician & $236(27.4)$ & $137(24.9)$ & $28(26.9)$ \\
\hline None & $218(25.3)$ & $126(22.9)$ & $22(21.2)$ \\
\hline \multicolumn{4}{|c|}{$\begin{array}{l}\text { FMG = family medicine group; } I Q R=\text { Interquartile range; } P C P=\text { primary care provider. } \\
\text { *Unless indicated otherwise. } \\
\text { tData were missing for } 5 \text { patients ( } 2 \text { inguinal hernia, } 1 \text { cryptorchidism, } 2 \text { hypospadias). } \\
\text { ‡Data were missing for } 56 \text { patients ( } 28 \text { inguinal hernia, } 21 \text { cryptorchidism, } 7 \text { hypospadias). }\end{array}$} \\
\hline
\end{tabular}

the 3 conditions, cryptorchidism patients were most likely to be seen by a specialist within targets, demonstrating $80.8 \%$ compliance, compared with $74.0 \%$ and $77.0 \%$ for inguinal hernia and hypospadias patients, respectively (Table 2). However, patients with cryptorchidism were least likely to receive surgery within targets, with only $49.9 \%$ actually operated within the recommended time compared with $67.1 \%$ and $64.4 \%$ for patients with inguinal hernia and hypospadias, respectively (Table 2).

Within the cohort of inguinal hernia patients, those younger than 1 year at the time of surgery had a guideline compliance rate of $60.0 \%$ to see a surgical specialist, while those older than 1 year had a compliance rate of $74.4 \%$ (Table 2). Cryptorchidism and hypospadias patients younger than 1 year of age had a $100 \%$ compliance rate, compared with those older than 1 year $(80.3 \%$

Fig. 2. Selection of cohort. $I C D=$ International Classification of Diseases; $P C P=$ primary care provider. 
Table 2. Proportion of patients seeing surgical specialist (WT1) and receiving surgery (WT2) within target times

\begin{tabular}{|c|c|c|c|c|c|c|}
\hline Condition, age & Median, d & $\begin{array}{c}\text { No. patients seen } \\
\text { within benchmark } \\
\text { time }\end{array}$ & $\begin{array}{l}\text { Total no. } \\
\text { patients } \\
\text { seen }\end{array}$ & $\begin{array}{l}\text { Patients seen within } \\
\text { benchmark time, \% }\end{array}$ & $\begin{array}{c}\text { Patients seen within } 1 \\
\text { week over benchmark } \\
\text { time, \% }\end{array}$ & $\begin{array}{c}\text { Patients seen within } \\
30 \mathrm{~d} \text { over benchmark } \\
\text { time, } \%\end{array}$ \\
\hline \multicolumn{7}{|l|}{ WT1 } \\
\hline Inguinal hernia, > $1 \mathrm{yr}$ & 17.0 & 590 & 793 & 74.4 & 77.8 & 84.2 \\
\hline Cryptorchidism, $<1 \mathrm{yr}$ & 19.0 & 13 & 13 & 100 & 100 & 100 \\
\hline Cryptorchidism, > 1 yr & 39.0 & 382 & 476 & 80.3 & 82.1 & 86.1 \\
\hline Total & - & 1064 & 1389 & 76.6 & 79.6 & 85.2 \\
\hline \multicolumn{7}{|l|}{ WT2 } \\
\hline Inguinal hernia,$<1 \mathrm{yr}$ & 22.0 & 13 & 26 & 50.0 & 57.7 & 69.2 \\
\hline Inguinal hernia, $>1 \mathrm{yr}$ & 50.0 & 564 & 834 & 67.6 & 70.3 & 76.3 \\
\hline Cryptorchidism, $<1$ yr & 74.0 & 18 & 19 & 94.7 & 94.7 & 94.7 \\
\hline
\end{tabular}

Table 3. Multivariable analysis for meeting WT1 Benchmark

\begin{tabular}{|lcc|}
\hline Condition, effect & OR $(95 \% \mathrm{Cl})$ & $p$ value \\
\hline All conditions & & \\
\hline Age at surgery & $0.94(0.91-0.97)$ & $<0.001$ \\
\hline PCP pediatrician v. family physician & $1.57(1.20-2.05)$ & 0.001 \\
\hline Inguinal hernia & & \\
\hline Age at surgery & $0.95(0.91-0.99)$ & 0.01 \\
\hline Cryptorchidism & & \\
\hline Age at surgery & $0.93(0.88-0.99)$ & 0.016 \\
\hline Surgeon specialty urology v. general surgery & $0.33(0.16-0.69)$ & 0.003 \\
\hline PCP pediatrician v. family physician & $2.14(1.24-3.70)$ & 0.006 \\
\hline Hypospadias & & \\
\hline Age at surgery & $0.84(0.71-0.99)$ & 0.035 \\
\hline Cl = confidence interval; OR = odds ratio; PCP = primary care provider; WT1 = wait time 1. & \\
\hline
\end{tabular}

for cryptorchidism and $74.0 \%$ for hypospadias) (Table 2). With regards to compliance rates to receive surgery, inguinal hernia patients had a rate of $50.0 \%$ for those younger than 1 year and $67.6 \%$ for those older than 1 year (Table 2). Cryptorchidism patients had rates of $94.7 \%$ (age $<1 \mathrm{yr}$ ) and $48.3 \%$ (age $>1 \mathrm{yr}$ ), whereas hypospadias patients had rates of $71.4 \%$ (age $<1 \mathrm{yr}$ ) or $63.3 \%$ (age $>1 \mathrm{yr}$ ) (Table 2). The percentage of patients seen by a surgical specialist within 1 week and 1 month over the recommended benchmark wait time was $79.6 \%$ and $85.2 \%$, respectively (Table 2). For patients receiving surgery, these values were $63.3 \%$ and $70.0 \%$, respectively (Table 2).
Table 4. Multivariable analysis for meeting WT2 benchmark

\begin{tabular}{|c|c|c|}
\hline Condition, effect & OR (95\% Cl) & $p$ value \\
\hline \multicolumn{3}{|l|}{ All } \\
\hline Age at surgery (yrs) & $0.97(0.94-0.99)$ & 0.040 \\
\hline $\begin{array}{l}\text { Surgeon specialty urology v. } \\
\text { general surgery }\end{array}$ & $0.70(0.55-0.88)$ & 0.002 \\
\hline $\begin{array}{l}\text { PCP pediatrician } v \text {. } \\
\text { family physician }\end{array}$ & $0.79(0.63-0.99)$ & 0.043 \\
\hline \multicolumn{3}{|l|}{ Inguinal Hernia } \\
\hline Age at surgery & $0.97(0.94-1.01)$ & 0.133 \\
\hline Rurality CA v. CMA & $1.98(1.14-3.44)$ & 0.082 \\
\hline Rurality rural v. CMA & $1.43(0.92-2.23)$ & 0.946 \\
\hline \multicolumn{3}{|l|}{ Cryptorchidism } \\
\hline Age at surgery & $0.98(0.94-1.03)$ & 0.379 \\
\hline \multicolumn{3}{|l|}{ Hypospadias } \\
\hline Age at surgery & $0.86(0.73-1.00)$ & 0.056 \\
\hline
\end{tabular}

\section{Inferential results}

Multivariate analysis results are presented in Table 3 for WT1 and in Table 4 for WT2. Univariate analysis results can be found in Appendix 1 .

Age at the time of surgery was a significant factor for all conditions for compliance with both WT1 and WT2, with the exception of WT2 for cryptorchidism patients (Table 3 and Table 4). As a patient's age increased, the odds of receiving care within either benchmark decreased for all conditions.

On univariate analysis, rurality was found to be significant only for inguinal hernia, for which patients living in CAs were more likely to receive surgery within acceptable time frames (Appendix 1). This significance remained in the multivariate analysis.

Regarding socioeconomic status, only hypospadias patients belonging to the third quartile were found to be 
significantly less likely to meet benchmark times to see a specialist on univariate analysis, though this significance also disappeared in the final model (Appendix 1).

The number of visits a patient had to the surgical specialist was significant only for WT2 for cryptorchidism patients in univariate analysis (being more likely to receive surgery within benchmarks; Appendix 1). However, no significance remained upon multivariate analysis.

Surgeon specialty appeared to be a contributing factor to whether a patient was seen and operated within targets or not. Univariate regression showed that cryptorchidism patients referred to a urologist were less likely to see that urologist within recommended times (Appendix 1) compared with a general surgeon. When all conditions were assessed together, patients under the care of a urologist also appeared to be less likely to receive surgery within benchmarks. Both phenomena remained statistically significant in the final adjusted analysis (Table 3 and Table 4).

When assessing the influence of the primary care physician's specialty, single variable regression showed that inguinal hernia and cryptorchidism patients under the care of pediatricians were statistically more likely to see a surgical specialist within P-CATS targets (Appendix 1). The same phenomenon occurred when all patients were assessed together. However, the final model maintained this result only for cryptorchidism patients and for all patients combined (Table 3). Additionally, the final model identified patients being referred by pediatricians as less likely to receive surgery on time (Table 4).

\section{Disability-adjusted life years}

The calculated total and mean DALY values for each condition are presented in Table 5. The total burden due to waiting beyond benchmarks for the 3 surgical conditions under study was 35 DALYs and the mean burden of waiting was 0.02 DALYs.

\section{Discussion}

The present study attempts to identify compliance with national surgical targets for 3 pediatric elective surgeries in the province of Quebec. While the literature on pediatric surgery wait time compliance with targets in Canada is limited, Szynkaruk and colleagues ${ }^{40}$ reported that $33 \%$ of children exceeded targets for WT1 at the Hospital for
Sick Children in Ontario between 2005 and 2011 (compared with $24.4 \%$ in our study). The same study found that $28 \%$ of children did not receive surgery within target times (compared with $39.3 \%$ in our study). These differences may be because of regional differences or because of a larger population in their study (39287 v. 1515), allowing for more accurate estimates.

Age was found to have an important effect on compliance with WT1 benchmarks for all conditions, both individually and combined, as well as on WT2 compliance for the combined cohort. In all cases, older patients were less likely to be seen within targets. Since shorter wait times are associated with better patient outcomes ${ }^{7,8}$ and fewer adverse events/complications in young patients, ${ }^{41,42}$ it is likely that younger children are ranked higher than older ones on surgical wait lists.

The rurality of a patient's residence appeared to have an effect on WT2 compliance for inguinal hernia patients. Those who resided in CAs (small cities with a population of 10000-100000) were more likely to receive surgery within national targets. This finding contrasts with that of Lau and colleagues, ${ }^{43}$ who analyzed the relationship between rurality and wait times for elective laparoscopic cholecystectomy, and a Statistics Canada report on access to health care services that found that residence location did not constitute a statistically significant factor affecting elective surgery. ${ }^{44}$ This finding may be explained by geographical differences in health care resources between urban areas and small cities in Quebec, as hypothesized by Nakhla and colleagues; ${ }^{35}$ however, more research is necessary to confirm such a link.

No significant association between socioeconomic status and wait time was found, which is consistent with the findings of other Canadian studies..$^{40,45-47}$ Additionally, no association between the number of visits to the specialist and compliance to wait time benchmarks was found in the final model.

Multivariate regression showed that the specialty of the primary care provider was a significant factor contributing to P-CATS compliance. This effect was noted for cryptorchidism patients as well as in the combined cohort. In both cases, patients being referred by a pediatrician were more likely to meet P-CATS WT1 targets. This may be because pediatricians have larger specialized referral networks and faster access to pediatric subspecialists than family physicians. Interestingly, being referred by a pediatrician appeared to have the opposite effect on WT2 target compliance in the combined cohort; these patients were

Table 5. Disability-adjusted life years resulting from non-compliance with P-CATS

\begin{tabular}{|c|c|c|c|c|c|c|}
\hline Condition & $\begin{array}{c}\text { DALYs due to } \\
\text { WT1 }\end{array}$ & $\begin{array}{c}\text { Average DALYs } \\
\text { due to WT1 }\end{array}$ & $\begin{array}{c}\text { DALYs due to } \\
\text { WT2 }\end{array}$ & $\begin{array}{c}\text { Average DALYs } \\
\text { due to WT2 }\end{array}$ & DALYs due to waiting & $\begin{array}{c}\text { Average DALYs due to } \\
\text { waiting }\end{array}$ \\
\hline Inguinal hernia & 6.249 & 0.008 & 9.137 & 0.011 & 15.386 & 0.018 \\
\hline Cryptorchidism & 3.317 & 0.007 & 12.869 & 0.023 & 16.187 & 0.029 \\
\hline Total & 10.092 & 0.007 & 25.239 & 0.017 & 35.331 & 0.023 \\
\hline
\end{tabular}


less likely to be seen in acceptable time frames. One explanation could be that pediatricians were more likely to refer patients to tertiary care centres, where surgical wait lists may be longer owing to a larger case mix, including more complex resource-intensive cases and other more urgent cases that may have taken priority over the common pediatric surgical cases examined in our study.

Similarly, the specialty of the surgeon also had a significant effect on compliance with targets for both wait times. Cryptorchidism patients being referred to a general surgeon were more likely to meet the targets than those referred to a urologist. Likewise, all patients seeing a general surgeon were more likely to meet WT2 targets. These effects are consistent with what was found by the Fraser Institute's 2018 report on wait times in adults: urologists had a median WT1 of 12.0 weeks compared with only 4.0 weeks for general surgeons and a median WT2 of 9.0 weeks compared with 7.1 weeks for general surgeons in Quebec. ${ }^{48}$ Furthermore, Jaakkimainen and colleagues $^{47}$ also reported that the median time spent waiting to initially see a urologist was longer than that to see a general surgeon. These findings likely reflect both workforce (insufficient numbers of urologists) and facility access (insufficient operating time allocated) issues.

The burden of waiting beyond national guidelines was also quantified using DALYs, showing that the highest total burden from waiting occurred in patients with cryptorchidism and inguinal hernia (16.19 and 15.39 DALYs in the studied population, respectively). The equivalent values per patient were 0.029 and 0.018 DALYs, respectively, compared with hypospadias patients who incurred 0.035 DALYs per patient, the highest average burden among the 3 conditions. These values are significantly lower than reported in another Canadian study (0.25 for hypospadias and 0.3 for cryptorchidism). ${ }^{23}$ This discrepancy is likely explained by the different purpose and methodology used; Poenaru and colleagues ${ }^{23}$ calculated DALYs based on actual minus ideal age at surgery, rather than the time spent waiting beyond benchmark targets, as was used in the present study. The total burden accrued was 35 DALYs, which can be thought of as 35 years of healthy life lost ${ }^{49}$ due to waiting beyond recommended times alone.

Currently, Quebec publishes wait time information for a limited list of medical conditions; $;^{13,14}$ however, these statistics are not specific to the pediatric population. Ontario has taken steps to report pediatric surgical wait times, but only for certain otolaryngological conditions. ${ }^{50}$ Publicly available online reporting tools for wait times are essential to identifying areas in need of improvement within the health care system and assisting policy makers in analyzing the effects of policy changes over time. Moreover, they can help better inform patients about standards for treatment. ${ }^{50}$ Our study suggests that there are areas that may benefit from policy changes in Que- bec, and expanding reporting tools to pediatric surgical conditions may prove beneficial to this point.

We feel that currently published P-CATS wait time targets are reasonable and, as such, improvements to timely access to surgical care are needed. Opportunities for improvement include better governmental oversight of surgical referral practices based on existing wait times of alternative providers as well as ongoing reassessment of subspecialist positions across the province based on workload and wait times.

\section{Limitations}

This study has several limitations. Owing to the occasionally inconsistent usage of ICD diagnostic codes and billing codes by family physicians and pediatricians, an assumption had to be made regarding the specific date of referral to a surgical specialist, which was chosen to be the most recent visit before the first surgical visit. It is therefore possible that compliance to see a surgical specialist within targets is even lower than the $76.6 \%$ we calculated. A similar limitation relates to the identification of the surgical decision date; as the RAMQ databases do not contain information on the actual date a surgery was booked, it was assumed that the last surgical visit before the intervention date was the surgical decision date. It is possible that an initial clinic visit may have resulted in not actually booking the surgery for another several months. Without the need for another visit, however, the common practice pattern in Quebec for the procedures chosen most frequently involves booking the surgery at the time of the initial specialist consultation (Dr. S. Emil, personal communication; Feb. 11, 2020). This assumption was likely less significant, as most patients $(82.7 \%)$ had only 1 prior visit with the surgeon.

Other patient and family factors that may influence wait times include the scheduling of clinic appointments or surgeries to coincide with school breaks. It is likely that these factors exist and are taken into account by both patient families and physicians. These potential delays are, however, generally short and, as such, would likely not affect wait times to any significant extent.

Regarding the calculation of DALYs, it must be noted that the DWs used were originally meant for all ages rather than for children only and that a range of DWs exists for some conditions. ${ }^{32}$ Given that the administrative databases used do not record level of severity for any condition, we used the values for mildly symptomatic conditions (e.g., 0.1 for inguinal hernias), which are more likely to reflect the majority of our pediatric population. Nonetheless, it is possible that certain patients experienced greater condition severity, and thus accrued a larger burden of disease from waiting. Similarly, it is possible that other studies analyzing the burden of disease used different DW values. 
Finally, the data used in this study were from 2010-2013. It is possible that health care policy and hospital practices have since changed, affecting wait times, and that these results may not be representative of the current health care state in Quebec.

\section{Conclusion}

This study has successfully generated data on actual wait times as well as compliance with national wait time targets for 3 pediatric elective surgeries in Quebec. In doing so, the burden of disease from waiting beyond the set targets was also assessed. Our results show that compliance rates are far from ideal and that efforts are needed to improve the proportion of patients seen within benchmark targets. We have identified that age and physician specialty significantly affect wait times, yet further studies are necessary to identify the root causes and explore specialty effects. Furthermore, publicly available reporting tools for surgical wait times should be expanded to the pediatric population in order to identify ongoing temporal trends and areas in need of improvement for health care policy makers.

Affiliations: From McGill University, Montreal, Que. (Arulanandam); StatSciences Inc., Notre-Dame-de-l'Île-Perrot, Que. (Dorais); the Division of General Pediatrics, Montreal Children's Hospital, McGill University Health Centre, Montreal, Que. (Li); and the Harvey E. Beardmore Division of Pediatric Surgery, Montreal Children's Hospital, McGill University Health Centre, Montreal, Que. (Poenaru).

Competing interests: None declared.

Funding: Brandon Arulanandam was funded by the Dr. Barkev and Mrs. Alice Andonian Research Bursary in Paediatrics. Patricia Li was funded by a New Investigator Salary Award and a grant from the Canadian Institutes of Health Research. Dan Poenaru was funded by a Junior Investigator Salary Award from the Fonds de Recherche du Québec en Santé.

Contributors: B. Arulanandam, P. Li and D. Poenaru designed the study and acquired the data, which all authors analyzed. B. Arulanandam wrote the article, which all authors reviewed. All authors gave final approval of the article to be published.

Content licence: This is an Open Access article distributed in accordance with the terms of the Creative Commons Attribution (CC BY-NC-ND 4.0) licence, which permits use, distribution and reproduction in any medium, provided that the original publication is properly cited, the use is noncommercial (i.e., research or educational use), and no modifications or adaptations are made. See: https://creativecommons.org/licenses/by-nc-nd/4.0/

\section{References}

1. Rychik J, Donaghue DD, Levy S, et al. Maternal psychological stress after prenatal diagnosis of congenital heart disease. 7 Pediatr 2013;162:302-7.e1.

2. McGarvey EL, Canterbury RJ, Cohen RB. Evidence of acute stress disorder after diagnosis of cancer. South Med f 1998;91:864-6.

3. Fitzsimons D, Parahoo K, Stringer M. Waiting for coronary artery bypass surgery: a qualitative analysis. F Adv Nurs 2000;32:1243-52.

4. Miller GG. Waiting for an operation: parents' perspectives. Can $\mathcal{F}$ Surg 2004;47:179-81.

5. Oudhoff JP, Timmermans DRM, Knol DL, et al. Waiting for elective general surgery: impact on health related quality of life and psychosocial consequences. BMC Public Health 2007;7:164.
6. Hanna BMN, Crump RT, Liu G, et al. Incidence and burden of comorbid pain and depression in patients with chronic rhinosinusitis awaiting endoscopic sinus surgery in Canada. 7 Otolaryngol Head Neck Surg 2017;46:23.

7. Miyanji F, Newton PO, Samdani AF, et al. Impact of surgical waiting-list times on scoliosis surgery: the surgeon's perspective. Spine 2015;40:823-8.

8. Lawrence JTR, Argawal N, Ganley TJ. Degeneration of the knee joint in skeletally immature patients with a diagnosis of an anterior cruciate ligament tear: Is there harm in delay of treatment? $A m \mathcal{F}$ Sports Med 2011;39:2582-7.

9. Hrivatakis G, Astfalk W, Schmidt A, et al. The timing of surgery for undescended testis - a retrospective multicenter analysis. Dtsch Arztebl Int 2014;111:649-57.

10. Barua B, Jacques D. The private cost of public queues for medically necessary care. Fraser Research Bulletin; 2019. Available: https://www. fraserinstitute.org/sites/default/files/private-cost-public-queues -medically-necessary-care-2019.pdf (accessed 2019 June 26).

11. Mendelsohn M. Canadians' Thoughts on Their Health Care System: Preserving the Canadian Model Through Innovation. Ottawa: Commission on the Future of Health Care in Canada; 2001.

12. Wright JG, Li K, Seguin C et al. Development of pediatric wait time access targets. Can $\mathcal{F}$ Surg 2011;54:107-10.

13. Wait times for priority procedures in Canada. Ottawa: Canadian Institute for Health Information; 2020. Available: https://www.cihi.ca/en/ wait-times-for-priority-procedures-in-canada (accessed 2019 June 26).

14. Accès aux services médicaux spécialisés - volet chirurgie. Québec: Ministère de la santé et services sociaux du Québec; 2005. Available: https://g74web.pub.msss.rtss.qc.ca/ (accessed 2019 June 26).

15. Paediatric Canadian Access Targets for Surgery (P-CATS). Toronto: Canadian Paediatric Surgical Wait Times; 2014. Available: http:// www.waittimealliance.ca/wp-content/uploads/2014/05/Paediatric_ SurgeryP-CATS_List.pdf (accessed 2019 May 29).

16. How Canada compares: results from the Commonwealth Fund's 2016 international health policy survey of adults in 11 countries. Ottawa: Canadian Institute for Health Information; 2017. Available: https://www.cihi.ca/sites/default/files/document/text-alternative -version-2016-cmwf-en-web.pdf (accessed 2019 May 29).

17. Wait Time Alliance. About us. WTA; 2014. Available: www. waittimealliance.ca/about-us/ (accessed 2019 Oct. 14).

18. Chang S-J, Chen JY-C, Hsu C-K, et al. The incidence of inguinal hernia and associated risk factors of incarceration in pediatric inguinal hernia: a nation-wide longitudinal population-based study. Hernia 2016;20:559-63.

19. Inguinal hernias and hydroceles in infancy and childhood: a consensus statement of the Canadian Association of Paediatric Surgeons. Paediatr Child Health 2000;5:461-2.

20. Hutson JM, Balic A, Nation T, et al. Cryptorchidism. Semin Pediatr Surg 2010;19:215-24.

21. Leslie SW, Villanueva CA. Cryptorchidism. StatPearls; 2019. Available: https://www.ncbi.nlm.nih.gov/books/NBK470270/ (accessed 2019 June 26).

22. Keays MA, Dave S. Current hypospadias management: diagnosis, surgical management, and long-term patient-centred outcomes. Can Urol Assoc 7 2017;11:S48-53.

23. Poenaru D, Pemberton J, Cameron BH. The burden of waiting: DALYs accrued from delayed access to pediatric surgery in Kenya and Canada. 7 Pediatr Surg 2015;50:765-70.

24. Covered services and accessory costs. Régie de l'assurance maladie du Québec; 2020. Available: http://www.ramq.gouv.qc.ca/en/citizens/ health-insurance/covered-services/Pages/covered-services-accessory -costs.aspx (accessed 2019 June 30).

25. Canadian TeleHealth Report. Canada's Health Informatics Association; 2013. Available: https://www.coachorg.com/en/resourcecentre/ resources/TeleHealth-Public-FINAL-web-040413-secured.pdf (accessed 2020 Jan. 28). 
26. Kass E. Timing of elective surgery on the genitalia of male children with particular reference to the risks, benefits, and psychological effects of surgery and anesthesia. Pediatrics 1996;97:590-4.

27. Kokorowski PJ, Routh JC, Graham DA, et al. Variations in timing of surgery among boys who underwent orchidopexy for cryptorchidism. Pediatrics 2010;126:e576-82.

28. Manzoni G, Bracka A, Palminteri E, et al. Hypospadias surgery: When, what and by whom? BfU Int 2004;94:1188-95.

29. Carmack A, Notini L, Earp BD. Should surgery for hypospadias be performed before an age of consent? 7 Sex Res 2016;53:1047-58.

30. Radmayr C, Dogan HS, Hoebeke P et al. Management of undescended testes: European Association of Urology/European Society for Paediatric Urology Guidelines. F Pediatr Urol 2016;12:335-43.

31. Braga LH, Lorenzo AJ, Romao RLP. Canadian Urological Association-Pediatric Urologists of Canada (CUA-PUC) guideline for the diagnosis, management, and followup of cryptorchidism. Can Urol Assoc 72017 ; 10.5489/cuaj. 4585.

32. Smith ER, Concepcion T, Lim S et al. Disability weights for pediatric surgical procedures: a systematic review and analysis. World $\mathcal{f}$ Surg 2018;42:3021-34.

33. Pampalon R, Hamel D, Gamache $\mathrm{P}$, et al. An area-based material and social deprivation index for public health in Québec and Canada. Can 7 Public Health 2012;103:S17-22.

34. Pampalon R, Gamache P, Hamel D. The Québec Index of Material and Social Deprivation - methodological follow-up, 1991 through 2006. Institut national de santé publique du Québec; 2011. Available: https:// www.inspq.qc.ca/pdf/publications/1258_QcIndexDeprivation1991-2006 .pdf (accessed 2019 July 4).

35. Nakhla M, Rahme E, Simard M et al. Risk of ketoacidosis in children at the time of diabetes mellitus diagnosis by primary caregiver status: a population-based retrospective cohort study. CMAF 2018;190:E416-21.

36. Milieux ruraux et urbains: Quelles différences de santé au Québec? Institut national de santé publique du Québec; 2020. Available: https://www.inspq.qc.ca/santescope/milieux-ruraux-urbains (accessed 2019 July 4).

37. Pampalon R, Martinez J, Hamel D. Does living in rural areas make a difference for health in Quebec? Health Place 2006;12:421-35.

38. McNiven C, Puderer H, Janes D. Census Metropolitan Area and Census Agglomeration influenced zones (MIZ): a description of the methodology. Ottawa: Statistics Canada; 2000.
39. Gamache P, Hamel D, Pampalon R. The material and social deprivation index: a summary. Institut national de santé publique du Québec; 2019. Available: https://www.inspq.qc.ca/sites/default/files/ santescope/indice-defavorisation/en/GuideMethodologiqueEN.pdf (accessed 2019 July 4).

40. Szynkaruk M, Stephens D, Borschel GH, et al. Socioeconomic status and wait times for pediatric surgery in Canada. Pediatrics 2014; 134:e504-11.

41. Ahn H, Kreder H, Mahomed N, et al. Empirically derived maximal acceptable wait time for surgery to treat adolescent idiopathic scoliosis. CMA7 2011;183:E565-70.

42. Chen LE, Zamakhshary M, Foglia RP, et al. Impact of wait time on outcome for inguinal hernia repair in infants. Pediatr Surg Int 2009;25:223-7.

43. Lau R, Vair BA, Porter GA. Factors influencing waiting times for elective laparoscopic cholecystectomy. Can 7 Surg 2007;50:34-8.

44. Clarke J. Difficulty accessing health care services in Canada Health at a Glance. Ottawa: Statistics Canada; 2016. Available: https://www150.statcan.gc.ca/n1/en/pub/82-624-x/2016001/ article/14683-eng.pdf?st=R3SQ9KaZ (accessed 2019 July 18).

45. Sutherland JM, Kurzawa Z, Karimuddin A, et al. Wait lists and adult general surgery: Is there a socioeconomic dimension in Canada? BMC Health Serv Res 2019;19:161.

46. Shortt SED, Shaw RA. Equity in Canadian health care: Does socioeconomic status affect waiting times for elective surgery? CMAJ 2003;168:413-6.

47. Jaakkimainen L, Glazier R, Barnsley J, et al. Waiting to see the specialist: patient and provider characteristics of wait times from primary to specialty care. BMC Fam Pract 2014;15:16.

48. Barua B, Jacques D, Collyer A. Waiting your turn: wait times for health care in Canada, 2018 Report. Fraser Institute; 2018. Available: https://www.fraserinstitute.org/sites/default/files/waiting-your-turn -2018.pdf (accessed 2019 July 18).

49. World Health Organization. Disability-adjusted life years (DALYs). WHO; 2019. Available: https://www.who.int/data/gho/indicator -metadata-registry/imr-details/158 (accessed 2020 Dec. 17).

50. Measuring pediatric wait times for surgeries in Ontario. Health Quality Ontario; 2019. Available: https://www.hqontario.ca/System -Performance/Measuring-System-Performance/Measuring-Pediatric -Wait-Times-for-Surgeries (accessed 2019 Aug. 15). 